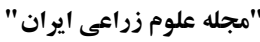

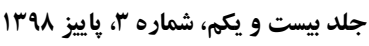

[Sorghum bicolor (L.) Moench] ارزيابى يايدارى عملكرد زنوتيبهاى سور كوم علوفهاى

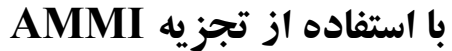

Evaluation of yield stability of forage sorghum [Sorghum bicolor (L.) Moench] genotypes using AMMI analysis

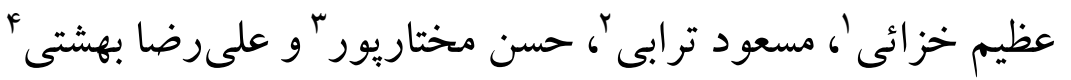

דكيده

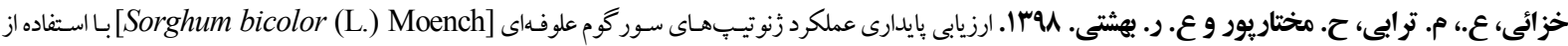

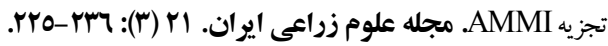

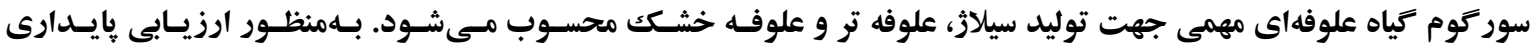
عملكرد شانزده رقم، لاين و هيبريد سور كوم علوفهاى، آزمايشهايى در قالب طرح بلوكىهاى كامل تصـادفى بـا سـه تكـرار طـى سال هاى 97 - هوا در مناطق كرج، اصفهان، كر كان و مشهد اجرا شد. نتايج تجزيه واريـانس مركـب دادههـا نشـان داد كـه اثـر مكان، سال، زنوتيب و اثر متقابل آنها بر عملكرد علوفه معنى دار بودنـد. نتـايج مقايسـه ميـانكينهـا نشـان داد كـه زنوتيـٍِهـاى

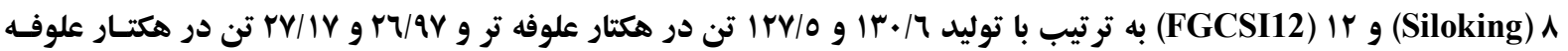

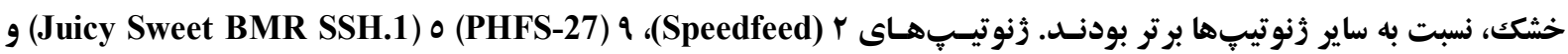

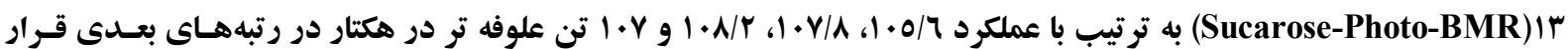
كرفتند. تجزيه واريانس به روش امى (AMMI) و برازش مؤلفههاى اصلى به اثر متقابل زنوتي ٍ و محيط نشـان داد كـه دو مؤلفـه

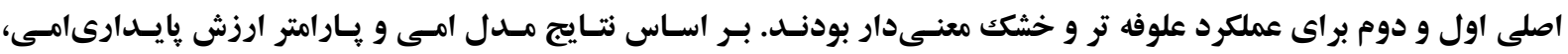

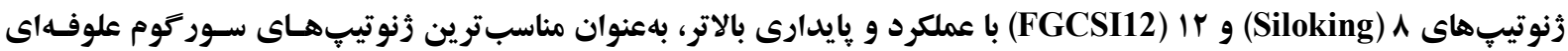
شناخته شدند.

وازههاى كليدى: تجزيه امى، سوركوم، عملكرد علوفه و مؤلفه هاى اصلى.

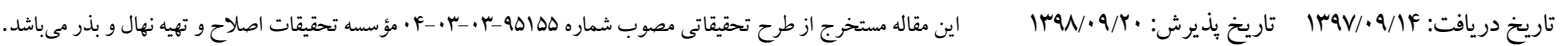

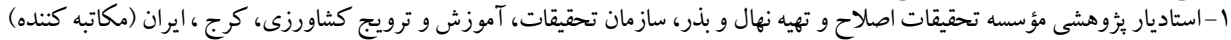

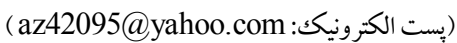

r-استاديار يزوهشى مركز تحقيقات كشاورزى و منابع طبيعى و آموزش اصفهان، سازمان تحقيقات، آموزش و ترويج كشاورزى، اصفهان، ايران

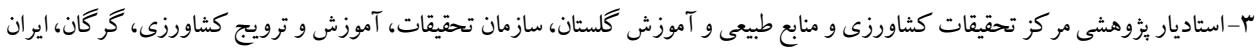

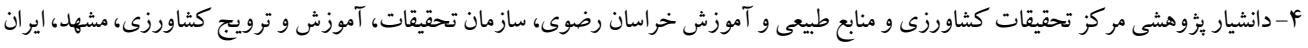


مؤلفـهـهـاى اصلىى، اثـر متقابـل زنوتيـبِ و محيط مـورد

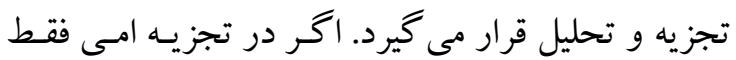

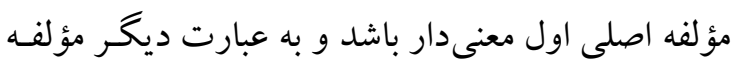

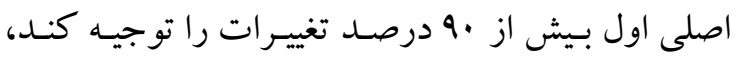

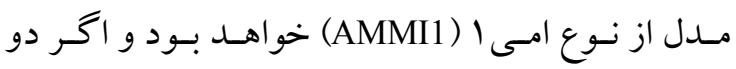
مؤلفه اصلى اول بيش از •ه درصـد تغييـرات را توجيـه

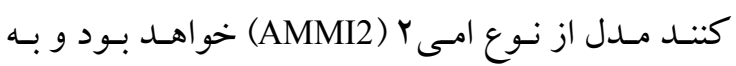
همين ترتيب براى مؤلفههاى بعدى اقدام مى شـود. حسال

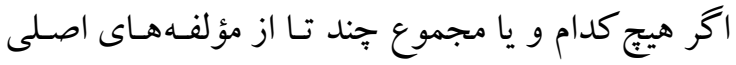
معنى

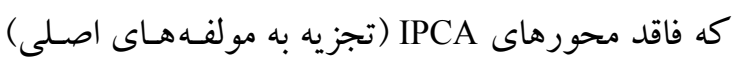
است و همان مدل تجزيه واريانس است (Gauch,1992).

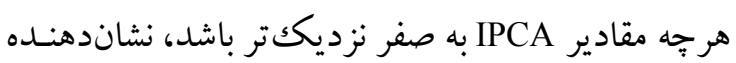

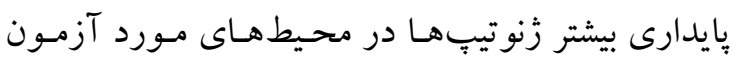

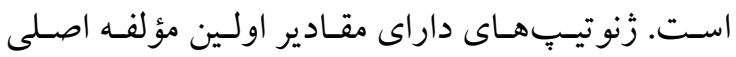

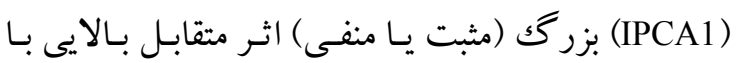

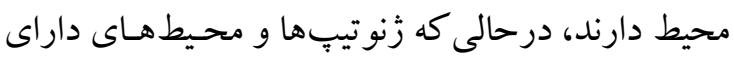

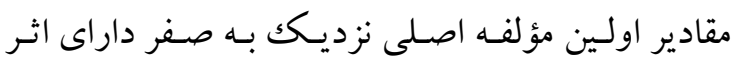

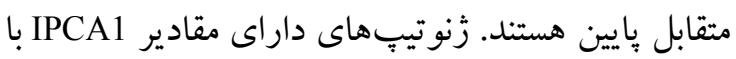

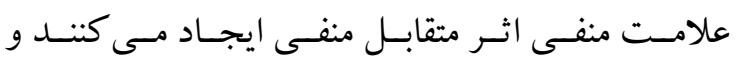
زرنو تيبِهاى با IPCA1 با علامت مثبت، اثر متقابل مثبـت ايجاد مى كنند. با صفا و همكاران (Basafa et al., 2015)

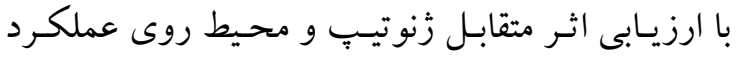

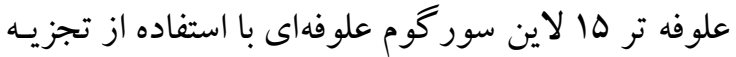
مدل اثرات اصلى افزايشى و ضرب بِـذير امى (AMMI) و نيز ارزيابى زنوتيّها، محيطها و اثرات متقابـل آنهـا با استفاده از آمارههاى بايدارى نشـان دادنـد كـه اثرات

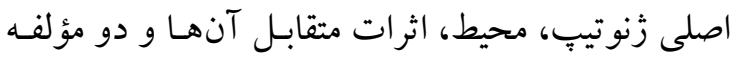

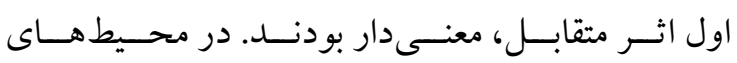

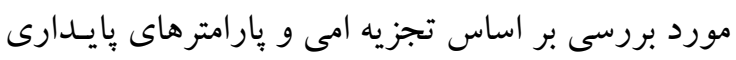

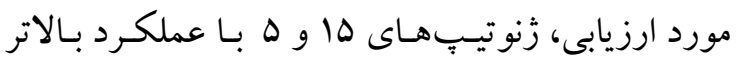

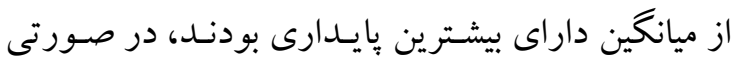

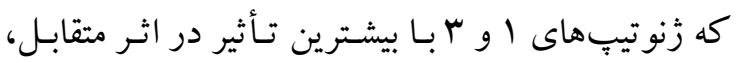

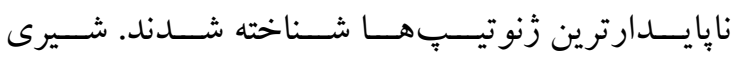

\section{مقدمه}

سور گوم [Sorghum bicolor (L.) Moench] نظر اهميت در بين گياهان غلاتى بعـد از گنـدم، بـرنج،

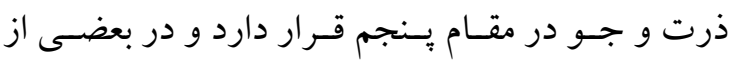
كشورها از جمله سودان در مقام اول و در ايالاتمتحده

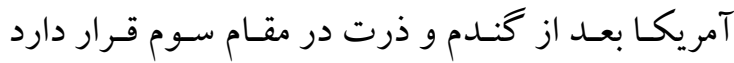

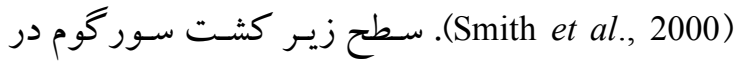

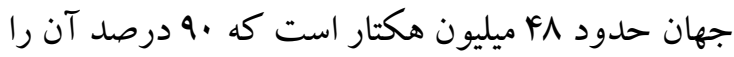

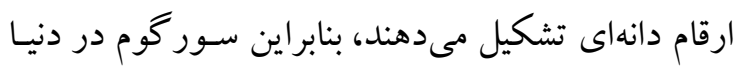

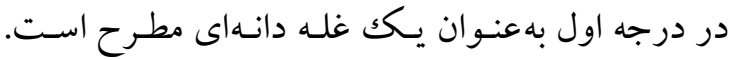

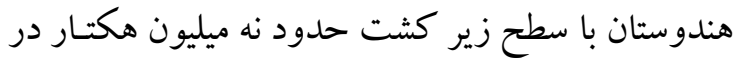

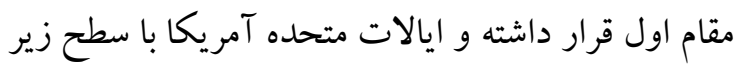

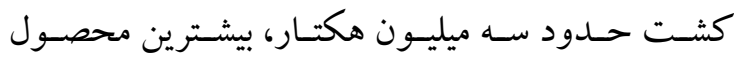

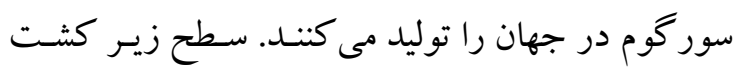

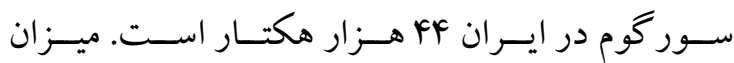

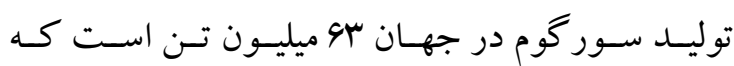

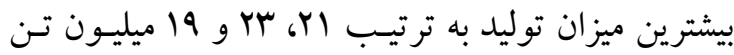

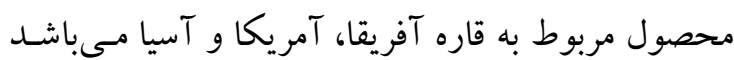

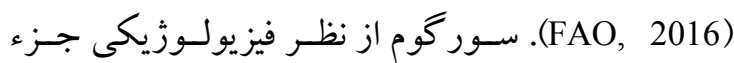

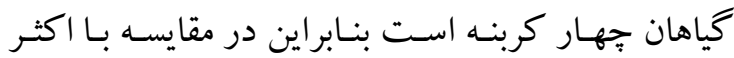

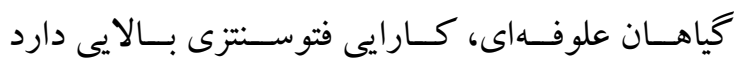

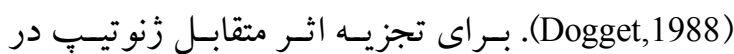

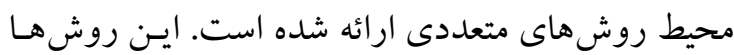

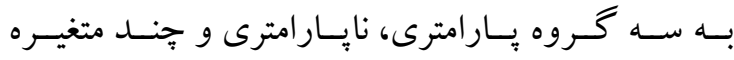
تقسيم بندى مى شوند (Gauch,1992). كز ارش شده است ونس

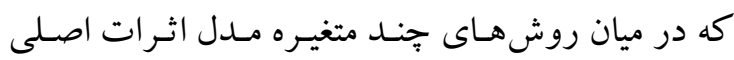

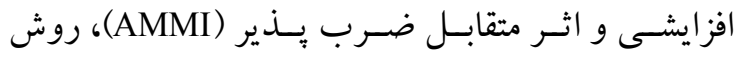

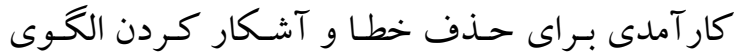
مناسب دادهها است (Yan and Hunt, 2002). اين روش هري

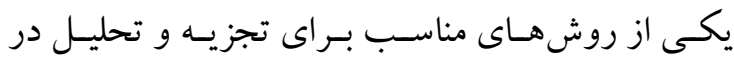

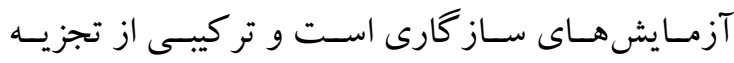

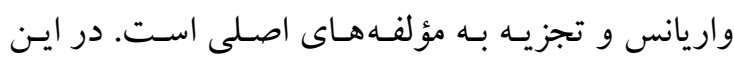

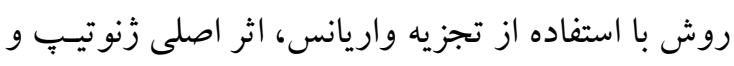

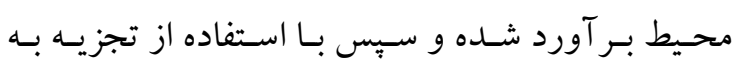




\section{" ارزيابى بايدارى عملكرد زنوتيجهاى سور كوم ...."}

\section{مواد و روشها}

آزمايش بر اساس طرح بلو كهـاى كامـل تصـادفى لو

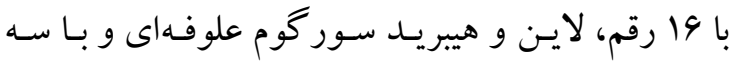

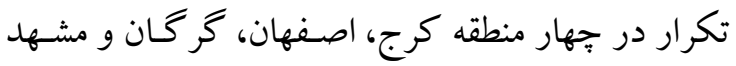

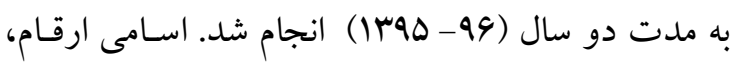
لاين ها و هيبريدهاى سور گوم علوفهاى همـراه بـا منشـاء آنها در جدول الارائه شده است. در هر سال، عمليـات

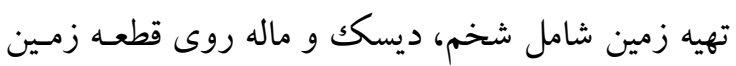
مورد نظر انجام و بـر اسـاس نتـايج آزمـون خـاكك، نيـاز كودى تعيين شد. تمام كودهاى فسفر و يتاس مورد نيـاز

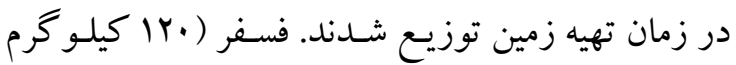

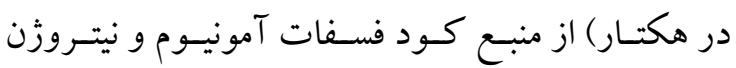

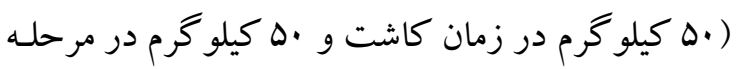

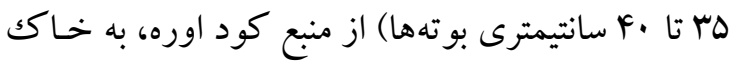
داده شدند. هر كرت شامل جهار خط كاشت ينج مترى

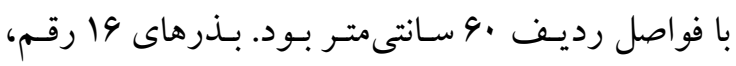

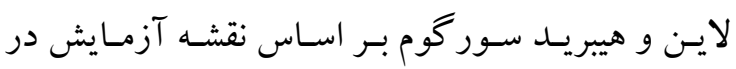

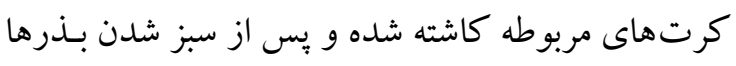

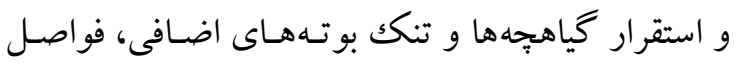
بين آنها بر اساس هشت سانتى متـر، تنكك و تنظيم شـد.

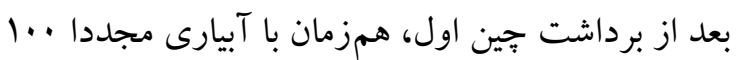

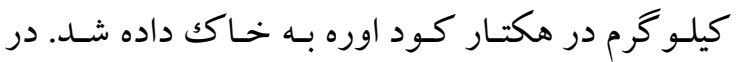
طول دوره رويش از صفات مهم زراعى از قبيـل ارتفـاع

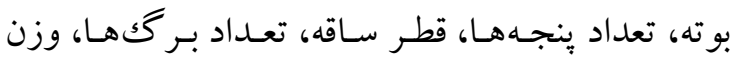

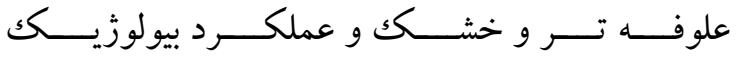

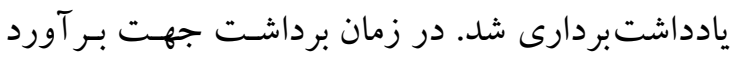
عملكرد، محصول دو خط وسط يس از حذف بـ حاشـيه،

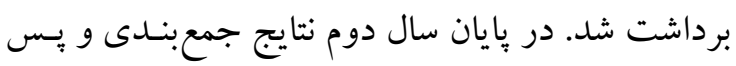

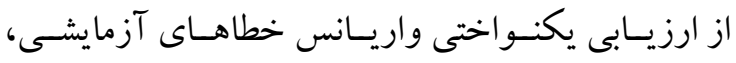

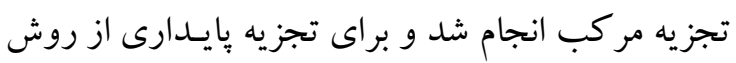

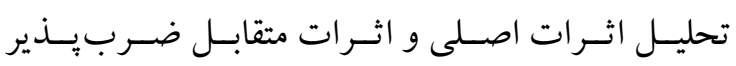

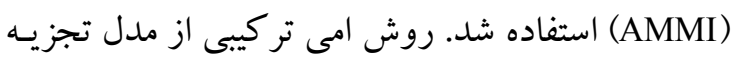

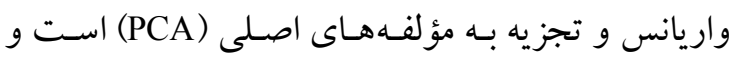
مدل آن بهصورت رابطه ا است (Gauch, 1992):
(Shiri, 2016) كزارش داد كه بر اساس منابع تغيير زنو تيبٍ و اثر متقابل

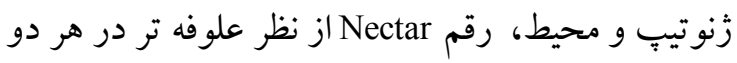

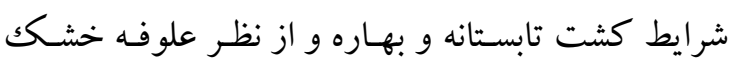
رقم Nectar در شرايط كشت تابستانه و رقم Speed feed

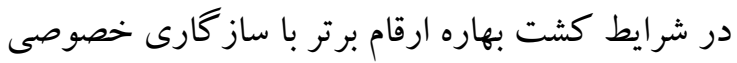

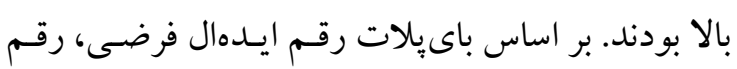

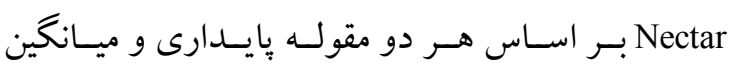

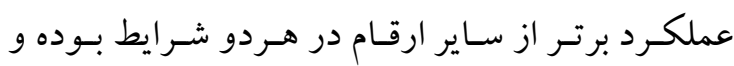
ساز گارى عمومى بالايى داشت.

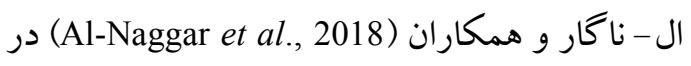

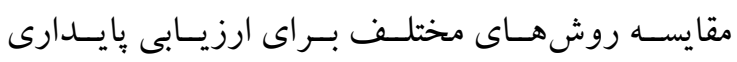

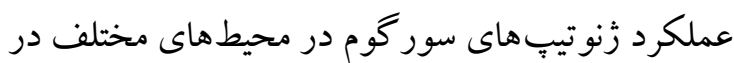

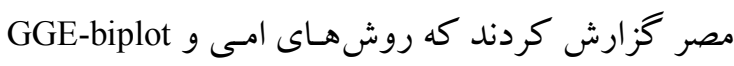

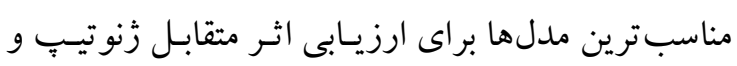

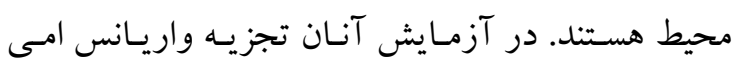

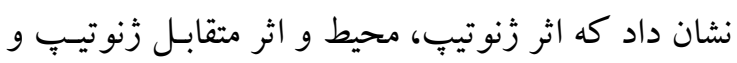

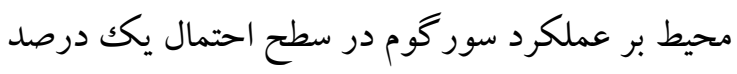

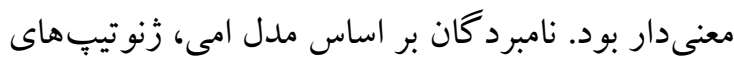
BTX TSC-20

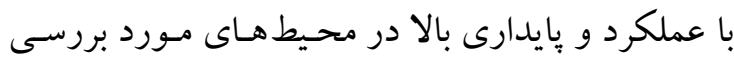

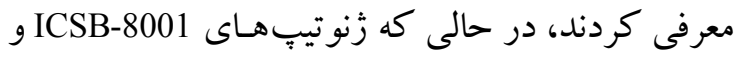
BTX- 407 متوسطى داشتند. روش هاى معرفى شده از نظر كـارايى تشـخيص رقـم

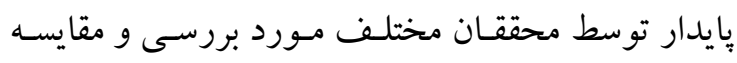

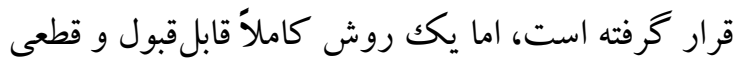

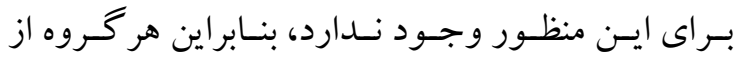

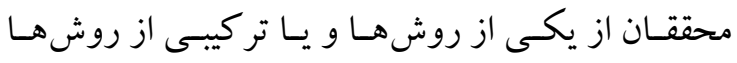

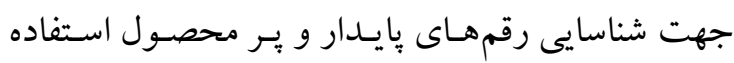
مى كنند. هدف از اين يُزوهش شناسايى رقم، لايسن و يـا

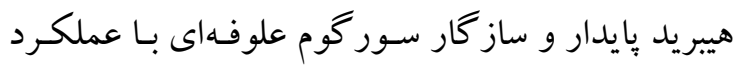
بالا بود. 
(Purchase,1997)

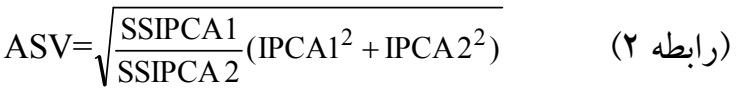
براى تجزيه دادهها از نرمافزارهـاى SAS 9.0 (بـراى

تجزيه واريـانس و مقايسـه ميـانكينهـا) و GENSTAT 12.0 (بر اى تجزيه يايدارى) اسـتفاده شـد. بـا اسـتفاده از معيار فاصله اقليدسى بر اساس دادههاى استاندارد شده و تجزيسه خوشــهاى بــا روش حســاقل واريــانس Ward كروهبندى زنوتيبِ هاى سور گوم انجام شد. روش Ward بهترين شكل گروهبندى (عـدم وجـود حالـت يلـهاى يـا زنجيرهاى) را داشته و به همين علت انتخاب شـد. بـرش دندرو ₹رام براساس بيشترين فاصله بين دو ادغام متـوالى

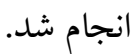

\section{نتايج و بحث}

ابتدا تجزيه واريانس ساده بـراى هـر محـيط بـهـور جداخانه انجام و آزمون يكنـو اختى واريـانس اشـتباهات آزمايشى انجام شده و بـراى دادههـاى دو سـال و جهـار مكان، فرض همكنى واريـانس خطـاى آزمـايش مـورد تأييد قرار كرفت. تجزيه مركب دادههـا يسس از آزمسون يكنواختى واريـانس اشـباهات انجـام شـد. نتـايج نشـان

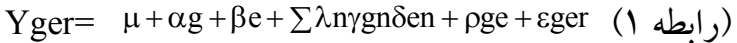
Yger

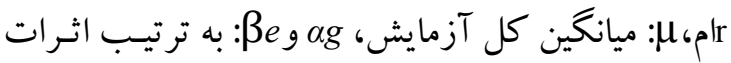

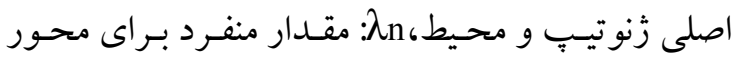

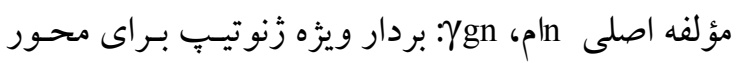
ام و pge مقــدار باقيمانــده يـا نــويز (Noise) و عger: عبارت مربوط به خطا هستند. براى بخش اول مدل امى ( ) يعنى بخش جمع بذير، از تجزيه واريـانس

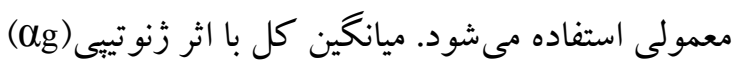

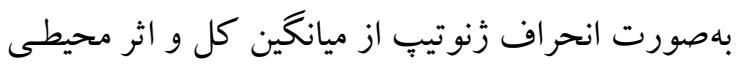
(Be)

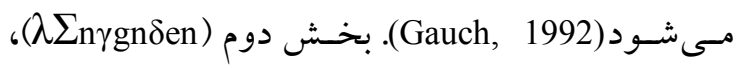
قسمت ضرب بذير مدل است كه از تجزيه به مؤلفههـاى اصلى (بهمنظور تجزيه اثر متقابـل زنوتيـبِ و محسيط بـهـ

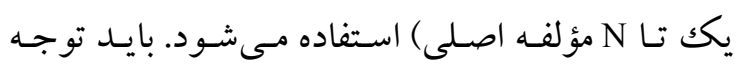
داشت كه در روش امى، محاسبات روى مقـادير اثرات

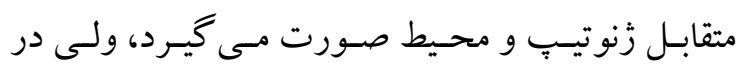
مؤلفههاى اصلى، محاسبات روى تفاضل دادههاى اصلى از ميانگين كـل دادههـا انجـام مـىشـود (Gauch,1988). بـــراى محاســبه آمــاره يايـــدارى ASV از رابطــــ

جدول ا - اسامى و منشاء زنوتيبِهاى سوركوم علوفهاى

Table1. Names and origin of forage sorghum genotypes

\begin{tabular}{|c|c|c|c|}
\hline شماره & $\begin{array}{c}\text { زنو تيبهاى سوركوم } \\
\text { Sorghum genotypes }\end{array}$ & $\begin{array}{l}\text { Origin } \\
\text { Oنشاء }\end{array}$ & $\begin{array}{c}\text { نام شر كت } \\
\text { Name of company }\end{array}$ \\
\hline 1 & CSSH.1 & USA & NAVAJOSEEDS \\
\hline 2 & Speed feed & Iran & SPII \\
\hline 3 & FGCSI09 & France & Euralis (ES) \\
\hline 4 & FS one BMR & USA & NAVAJOSEEDS \\
\hline 5 & Juicy Sweet BMR SSH.1 & USA & NAVAJOSEEDS \\
\hline 6 & Juicy Sweet BMR SSH.2 & USA & NAVAJOSEEDS \\
\hline 7 & Titan & Serbia & Neginsabz borna \\
\hline 8 & Siloking & Serbia & Neginsabzborna \\
\hline 9 & PHFS27 & ICRISAT (India) & Pajpal \\
\hline 10 & PFS21 & ICRISAT (India) & Pajpal \\
\hline 11 & FGCSI10 & France & Euralis (ES) \\
\hline 12 & FGCSI12 & France & Euralis (ES) \\
\hline 13 & Sucarose-Photo-BMR & USA & NAVAJOSEEDS \\
\hline 14 & KFS2 & Iran & SPII \\
\hline 15 & KFS18 & Iran & SPII \\
\hline 16 & Pegah & Iran & SPII \\
\hline
\end{tabular}


و و آ (Juicy Sweet BMR SSH.1)ه (PHFS-27)

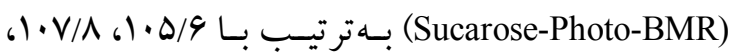

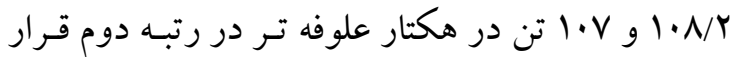

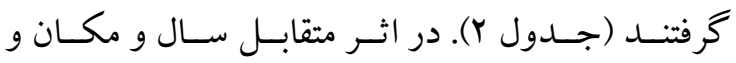

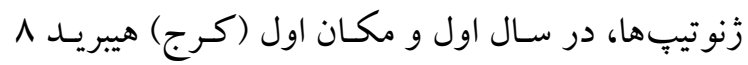

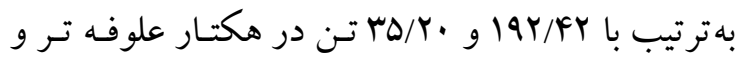

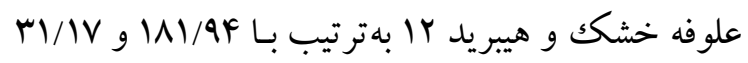
تن در هكتار علوفه تـر و علوفـه خشكك، داراى برتـرى بودند. با توجه به نتايج حاصل از تجزيه مركب و مقايسه

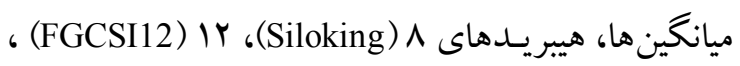
Ir (Juicy Sweet BMR SSH.1) ه (Speed feed) و 9 (Sucrose Photo BMR) تر و خشكك بالاترى بودند و بـهـعـوان هيبريسـداى برتـر شناسايى شدند. بـا توجـه بـه معنـى دار شـدن اثـر متقابـل زَنوتيـبِ و محيط، تجزيه واريانس معمولى قادر به توجيـه بايسـارى زنو تيسبِهـا نمسىباشــ؛ بنـابراين لازم بـود بـا اسـتفاده از روش هاى تجزيه بيايدارى، اثر متقابـل زنوتيسبِ و محسيط
داد كه مكانها، سالها، زُنوتيـبٍ هـا و اثر متقابـل آنهـا از نظر اثر بـر عملكـرد علوفـه تـر و علوفـه خشك در سطح احتمـال يـك در صـد داراى تفـاوت معنى دارى بودند. تفاوت بين مكـانهـا نشـان دهنـده غيريكنو اخـت بـودن آنهـا اسـت. نتـايج مقايسـه ميـانكين هــا نشـان

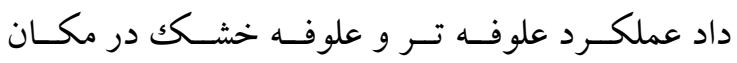
دوم (اصـفهان) نسـبت بـهـ سـاير منــاطق داراى برتــىى بسود (جـدول Y). معنسى دار بـودن اثر سـال بـر عملكـرد

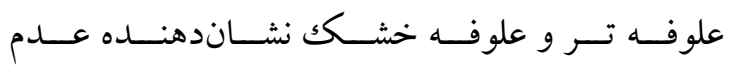
همسانى شرايط محيطى طى دو سـال آزمايش اسـت.

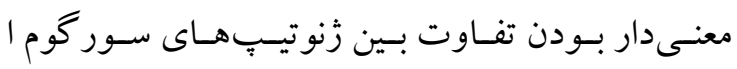

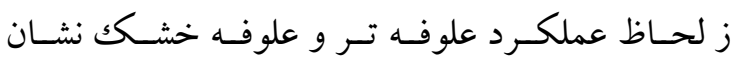

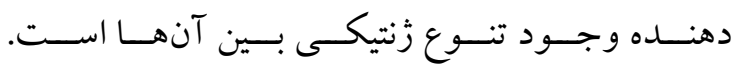

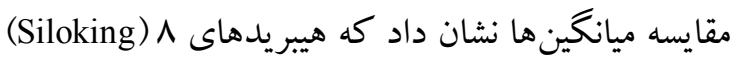
و

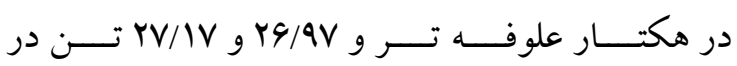

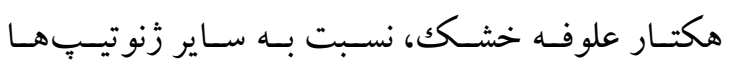

داراى برتـرى بودنــ و هيبريـدهاى Y (Speed feed)،

جدول Y- مقايسه ميانگين عملكرد علوفه تر و علوفه خشك زنوتيبٍ هاى سورگوم علوفهاى در دو سال

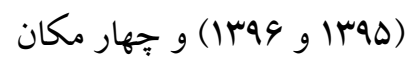

Table 2. Mean comparison of fresh and dry forage yield of forage sorghum genotypes

\begin{tabular}{|c|c|c|c|c|}
\hline \multicolumn{2}{|c|}{ Treatments } & تيمارهاى آزمايشى & \multirow[t]{2}{*}{ 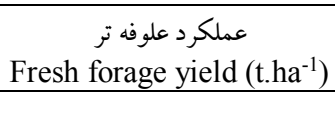 } & \multirow[t]{2}{*}{ 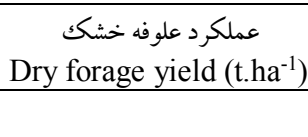 } \\
\hline & & سال Year سال & & \\
\hline \multirow{2}{*}{ Year } & \multirow{2}{*}{ 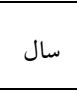 } & 2016 & $110.1 \mathrm{a}$ & $23.3 \mathrm{a}$ \\
\hline & & $2017 \quad$ Ira9 & $90.8 b$ & $20.8 b$ \\
\hline \multirow{4}{*}{ Location } & \multirow{4}{*}{ مكان } & Kرج Karaj & $105.6 \mathrm{~b}$ & $21.7 \mathrm{~b}$ \\
\hline & & اصفهان Isfahan & $132.1 \mathrm{a}$ & $27.2 \mathrm{a}$ \\
\hline & & Gركان Gorgan & $100.2 b$ & $21.2 \mathrm{~b}$ \\
\hline & & مشهد Mashhad & $63.8 \mathrm{c}$ & $18.3 \mathrm{c}$ \\
\hline \multirow{4}{*}{2016} & \multirow{4}{*}{$1 \% 90$} & Kرج & $135.3 \mathrm{a}$ & $26.6 b$ \\
\hline & & اصفهان Isfahan & $124.4 \mathrm{~b}$ & $25.5 b$ \\
\hline & & Gر كان Gorgan & $124.4 \mathrm{~b}$ & $25.5 b$ \\
\hline & & مشهد Mashhad & $56.0 \mathrm{~d}$ & $15.7 \mathrm{~d}$ \\
\hline \multirow{4}{*}{2017} & \multirow{4}{*}{ Irag } & Kرج & $75.9 \mathrm{c}$ & $16.8 \mathrm{~d}$ \\
\hline & & اصفهان Isfahan & $139.7 \mathrm{a}$ & $28.8 \mathrm{a}$ \\
\hline & & Gركان Gorgan & $75.9 \mathrm{c}$ & $16.8 \mathrm{~d}$ \\
\hline & & Mashhad مشهد & $71.6 \mathrm{c}$ & $20.9 c$ \\
\hline
\end{tabular}




\begin{tabular}{|c|c|c|}
\hline \multicolumn{3}{|c|}{ Table 2. (Continued) } \\
\hline $\begin{array}{c}\text { زنوتيبهاى سورگوم } \\
\text { Sorghum genotypes }\end{array}$ & $\begin{array}{c}\text { عملكرد علوفه تر forage yield (t.ha-1) } \\
\text { Fresh forat }\end{array}$ & 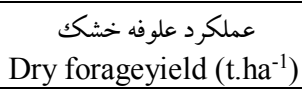 \\
\hline CSSH.1 & $88.1 \mathrm{de}$ & $20.0 \mathrm{ef}$ \\
\hline Speed feed & $105.6 b$ & $23.4 b-d$ \\
\hline FGCSI09 & $99.7 \mathrm{bc}$ & $21.0 \mathrm{c}-\mathrm{f}$ \\
\hline FS one BMR & $90.6 \mathrm{~cd}$ & $21.2 \mathrm{c}-\mathrm{f}$ \\
\hline Juicy Sweet BMR SSH.1 & $108.2 b$ & $24.4 \mathrm{ab}$ \\
\hline Juicy Sweet BMR SSH.2 & $96.1 \mathrm{~cd}$ & $20.1 \mathrm{ef}$ \\
\hline Titan & $93.2 \mathrm{~cd}$ & $22.9 b-e$ \\
\hline Siloking & $130.6 \mathrm{a}$ & $26.9 \mathrm{a}$ \\
\hline PHFS-27 & $107.8 \mathrm{~b}$ & $23.6 \mathrm{bc}$ \\
\hline PFS-21 & $80.5 \mathrm{e}$ & $18.2 \mathrm{f}$ \\
\hline FGCSI10 & $95.7 \mathrm{~cd}$ & $21.2 \mathrm{c}-\mathrm{f}$ \\
\hline FGCSI12 & $127.5 \mathrm{a}$ & $27.1 \mathrm{a}$ \\
\hline Sucarose-Photo-BMR & $107.0 \mathrm{~b}$ & $22.6 b-e$ \\
\hline KFS-2 & $87.1 \mathrm{de}$ & $20.3 d-f$ \\
\hline KFS-18 & $92.9 \mathrm{~cd}$ & $20.7 \mathrm{c}-\mathrm{f}$ \\
\hline Pegah & $95.8 \mathrm{~cd}$ & $19.6 \mathrm{ef}$ \\
\hline
\end{tabular}

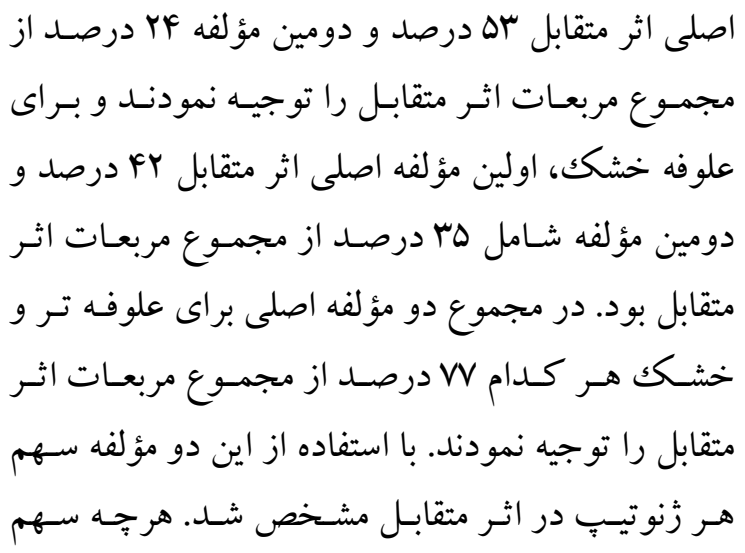

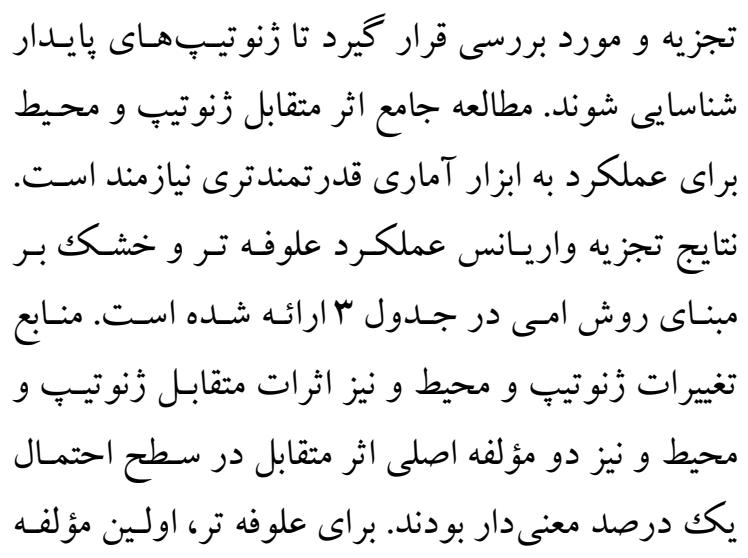

جدول س- تجزيه واريانس عملكرد علوفه تر و علوفه خشكك زنو تيبٍهاى سوركوم علوفهاى با استفاده از روش امى

Table 3. Analysis of variance for fresh and dry forage yield of forage sorghum genotypes using AMMI method

\begin{tabular}{|c|c|c|c|}
\hline \multirow[b]{2}{*}{ منابع تغيير } & \multirow[b]{2}{*}{$\begin{array}{c}\text { درجه آزادى } \\
\text { df }\end{array}$} & \multicolumn{2}{|c|}{ ميانغين مربعات (MS) } \\
\hline & & $\begin{array}{c}\text { عملكرد علوفه تر } 1 \text { عresh forage yield (t.ha-1) } \\
\text { Freld }\end{array}$ & 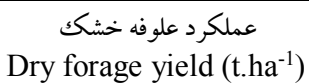 \\
\hline Total & 383 & 1546 & 57.3 \\
\hline Fenotypes (G) رنوتيب & 15 & $4505^{* *}$ & $155^{* *}$ \\
\hline محيط Environment & 7 & $54305^{* *}$ & $1283.4^{* *}$ \\
\hline Block & 16 & 346 & 24.5 \\
\hline زَنوتيب × محيط & 105 & $791^{* *}$ & $63^{* *}$ \\
\hline مؤلفه اصلى اول & 21 & $2062^{* *}$ & $131.9^{* *}$ \\
\hline مؤلفه اصلى دوم & 19 & $1012^{* *}$ & $120^{* *}$ \\
\hline Residuals باقيمانده & 65 & 316 & 24.1 \\
\hline Error & 240 & 233 & 15.1 \\
\hline
\end{tabular}


زنوتيبّهاى داراى ساز كارى خصوصى بـه محيطهـاى

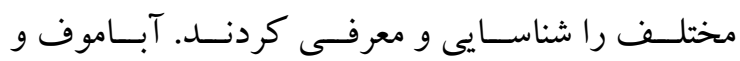

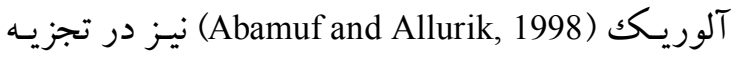
امسى ارقـام بـرنج آثـار اصـلى محسيط و زنوتيسب و و آثـار

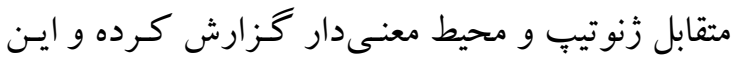
مدل را مناسب ترين مدل براى بررسى اثر متقابـل اعـلام كردند.

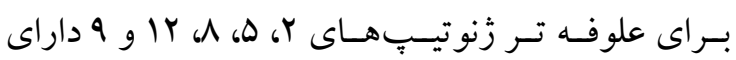
IPCA1 اين زنوتيبٍها مناسب و بيشتر از ميانگين كل بـود و بـالا

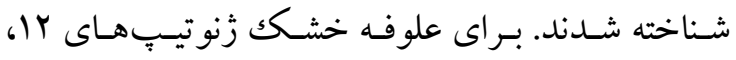

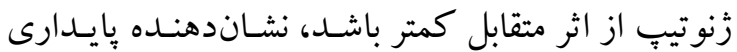

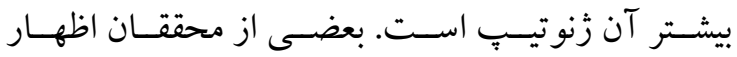

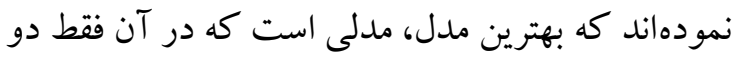

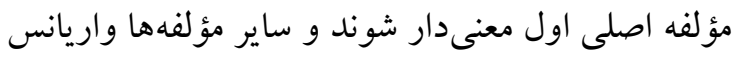

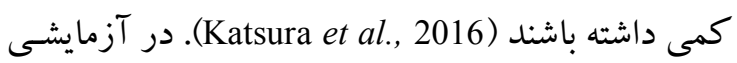

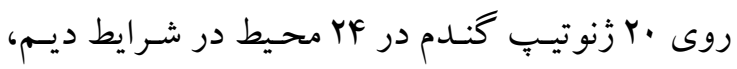

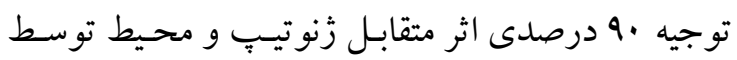

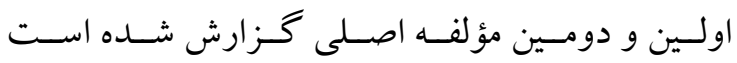
Roostaei et al., 2014)

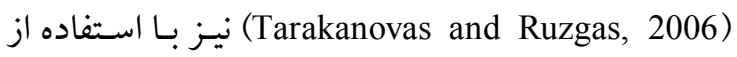

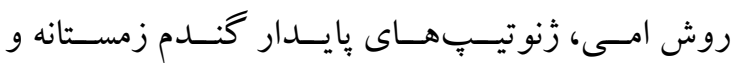

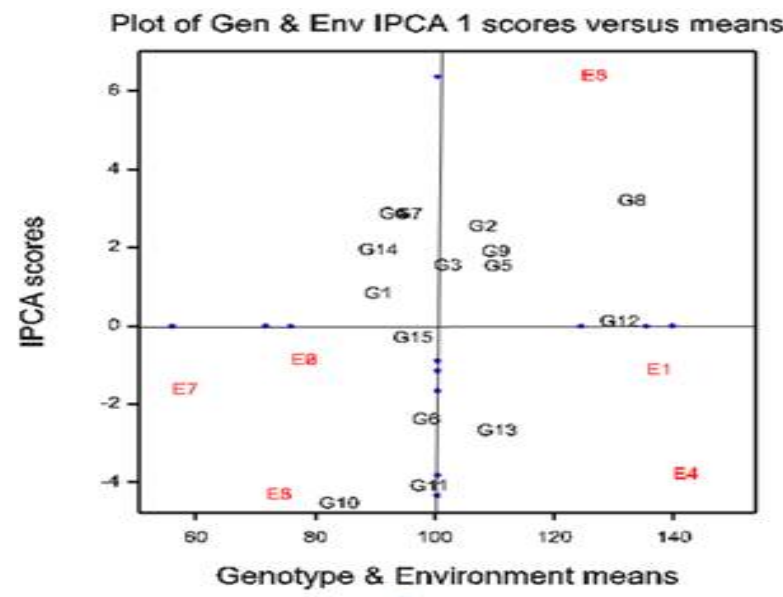

Plot of Gen \& Env IPCA 1 scores versus means

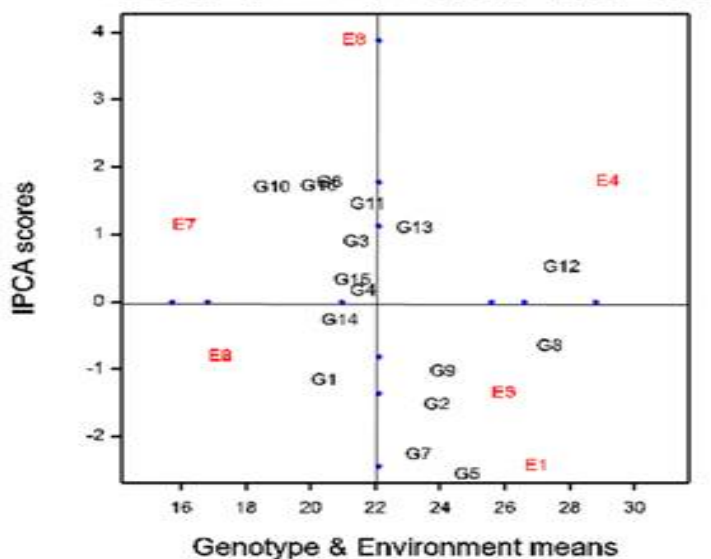

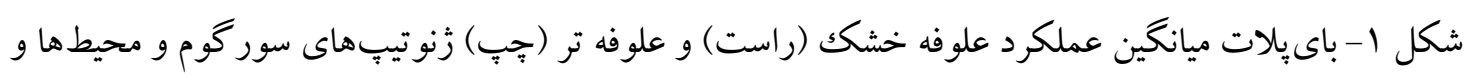

$$
\text { مقادير اولين مؤلفه اصلى آنها }
$$

Fig.1. Biplot of mean of dry (right) and fresh (left) forage yield of sorghum genotypes and environments and the values of the first principal components of them

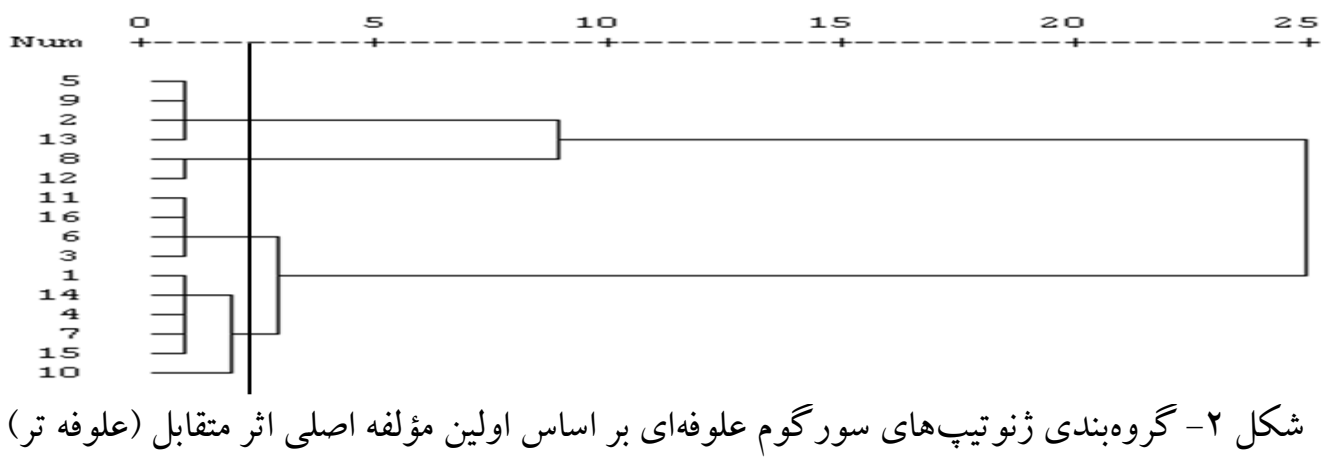

Fig. 2. Grouping of forage sorghum genotypes based on the first principal component of interaction (fresh forage) 


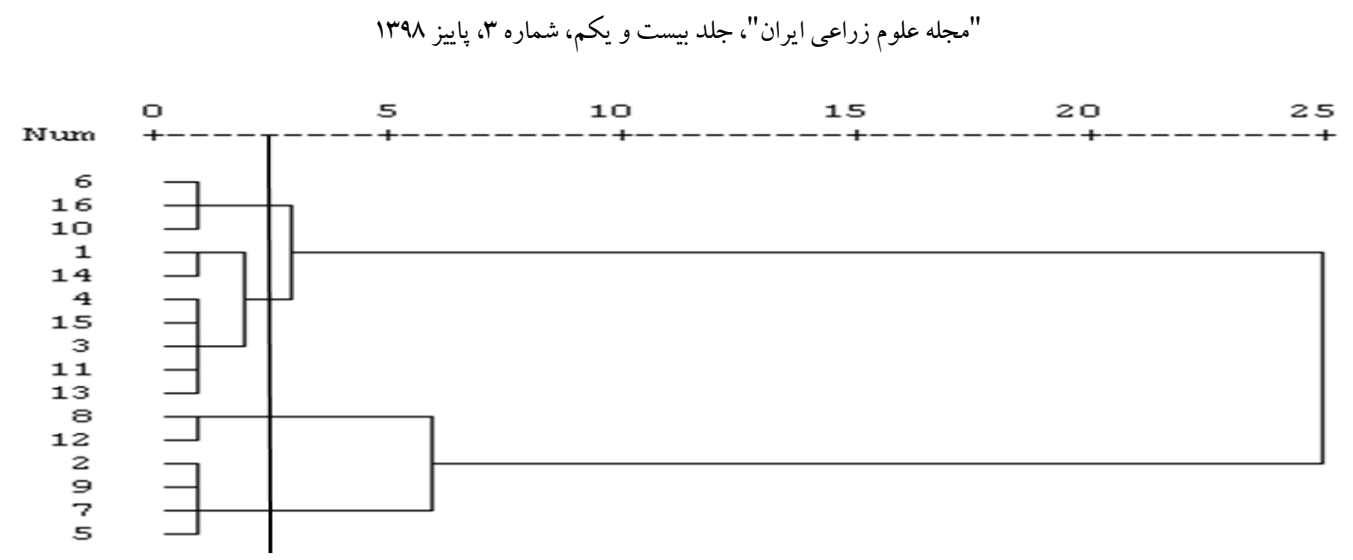

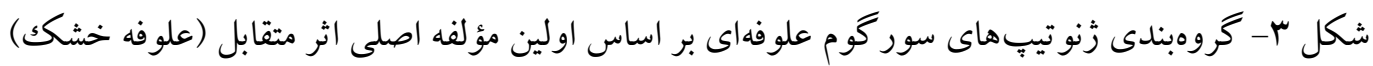

Fig. 3. Grouping of forage sorghum genotypes based on the first principal component of interaction (dry forage)

دو جفت از دادهها روى محور ها نمـايش داده شـدهانــ.

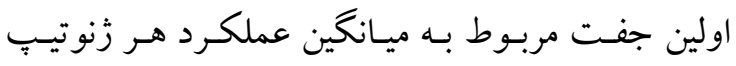

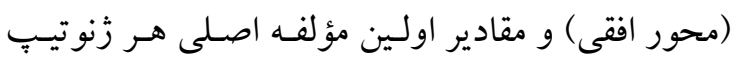

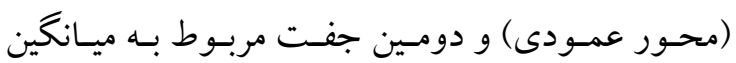

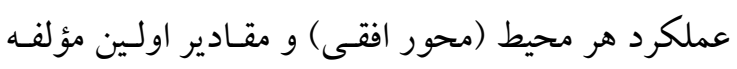

اصلى هر محيط (محسور عمـودى) مسياشـند. بـهنظور

تجزيه واكنش زنوتييى (استفاده همز زمان از تفكيكك هاى

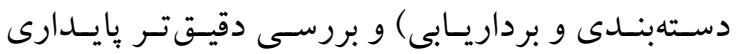

زرنوتيبِها و محيطها، تجزيه خوشهاى بر اسـاس مقـادير
F و ها داراى كمتـرين مقــدار IPCA1 بـوده و عملكـرد علوفه خشك بالايى هم داشتند (جدول F).

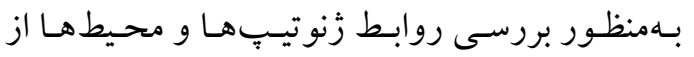

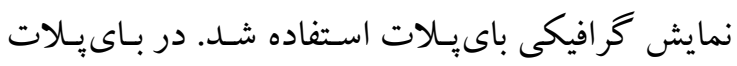

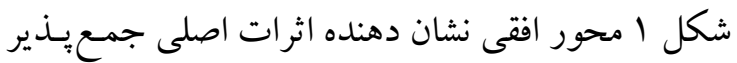

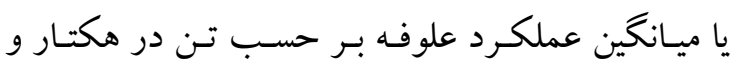
محور عمودى اثرات متقابل ضربى يا مقادير اولين مؤلفه

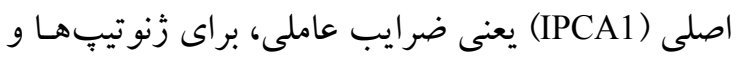
محيطها بهطور جدا كانه مىباشد. در باى يـلات مـذكور

جدول F- مقادير مؤلفه هاى اصلى اول و دوم و بِارامتر ارزش بِيدارى امى (ASV) براى زنوتيٍ هاى سور گوم علوفهاى

Table 4. The first and second main components and ASV parameter for forage sorghum genotypes

\begin{tabular}{|c|c|c|c|c|c|c|c|c|}
\hline \multirow[b]{2}{*}{ زرنوتيبهاى سوركوم } & \multicolumn{4}{|c|}{$\begin{array}{c}\text { علوفه } \\
\text { Fresh forage } \\
\end{array}$} & \multirow{2}{*}{$\begin{array}{c}\text { عملكرد } \\
\text { Yield } \\
\left(\text { t.ha }^{-1}\right)\end{array}$} & \multicolumn{2}{|c|}{$\begin{array}{l}\text { علوفه خشك } \\
\text { Dry forage }\end{array}$} & \multirow[b]{2}{*}{ ASV } \\
\hline & $\begin{array}{l}\text { Yield } \\
\left(\text { t.ha }^{-1}\right)\end{array}$ & IPCA1 & IPCA2 & ASV & & IPCA1 & IPCA2 & \\
\hline CSSH.1 & 88.1 & 0.80 & 2.27 & 5.89 & 20.0 & -1.17 & 0.99 & 1.75 \\
\hline Speed feed & 105.6 & 2.52 & 2.96 & 4.16 & 23.4 & -1.54 & 1.14 & 2.18 \\
\hline FGCSI09 & 99.7 & 1.52 & -2.28 & 7.61 & 21.0 & 0.88 & -0.06 & 1.01 \\
\hline FS one BMR & 90.6 & 2.84 & -4.14 & 3.04 & 21.2 & 0.15 & -2.79 & 3.19 \\
\hline Juicy Sweet BMR SSH.1 & 108.2 & 1.50 & 1.33 & 5.92 & 24.4 & -2.57 & 0.70 & 3.03 \\
\hline Juicy Sweet BMR SSH.2 & 96.1 & -2.42 & -3.06 & 4.32 & 20.1 & 1.76 & -0.64 & 2.13 \\
\hline Titan & 93.2 & 2.83 & 0.29 & 5.82 & 22.9 & -2.28 & 1.13 & 2.90 \\
\hline Siloking & 130.6 & 3.17 & 2.16 & 3.09 & 26.9 & -0.66 & -0.43 & 0.90 \\
\hline PHFS27 & 107.8 & 1.87 & 0.80 & 7.86 & 23.6 & -1.04 & -1.83 & 2.40 \\
\hline PFS21 & 80.6 & -4.56 & -2.46 & 7.25 & 18.2 & 1.69 & 0.25 & 1.95 \\
\hline FGCSI10 & 95.8 & -4.12 & 2.42 & 2.26 & 21.2 & 1.44 & 2.56 & 3.35 \\
\hline FGCSI12 & 127.5 & 0.09 & 1.49 & 4.21 & 27.1 & 0.51 & 0.03 & 0.58 \\
\hline Sucarose-Photo-BMR & 107.0 & -2.70 & -0.63 & 4.28 & 22.6 & 1.09 & 0.42 & 1.33 \\
\hline KFS2 & 87.2 & 1.92 & -2.07 & 2.39 & 20.3 & -0.28 & -1.50 & 1.74 \\
\hline KFS18 & 93.0 & -0.33 & -1.54 & 8.36 & 20.7 & 0.31 & -1.16 & 1.37 \\
\hline Pegah & 95.9 & -4.92 & 2.48 & 5.89 & 19.6 & 1.71 & 1.19 & 2.38 \\
\hline
\end{tabular}


جدول ه- جهار زنوتيب برتر سور گوم علوفهاى به ترتيب اولويت براى هر محيط (تركيب سال و مكان) با استفاده از روش امى

Table 5. The top four genotypes of forage sorghum in the order of priority for each environment (combination of year and location) using AMMI method

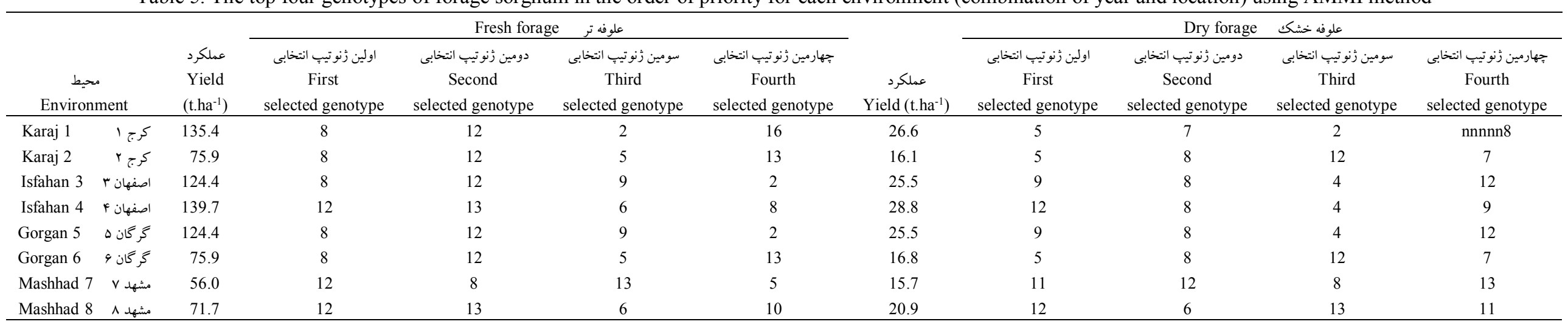


واريانس سـاده و تجزيـه بـه مؤلفـهــاى اصلمى نـام بـرد.

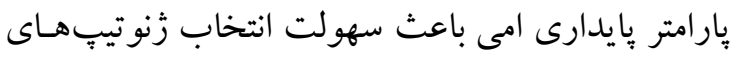

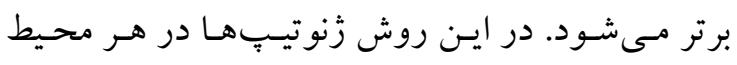

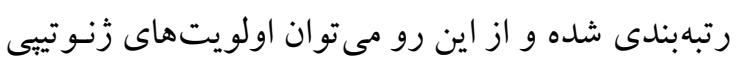

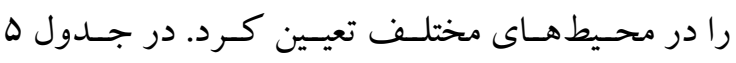

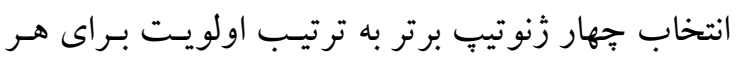

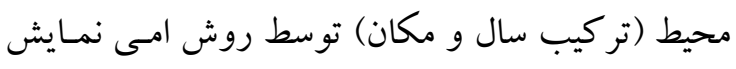

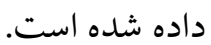

\section{نتيجه كيرى}

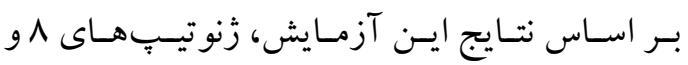

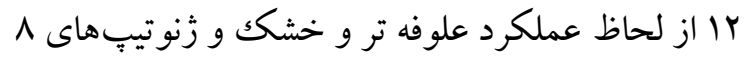

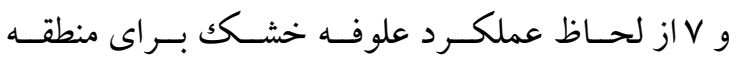

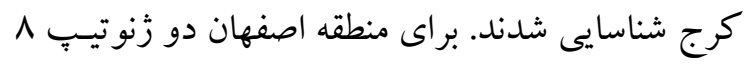

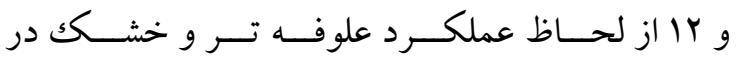

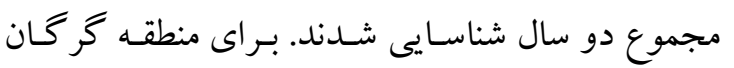

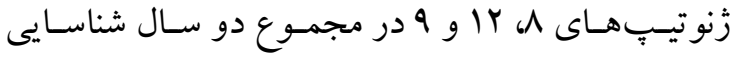

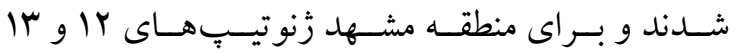

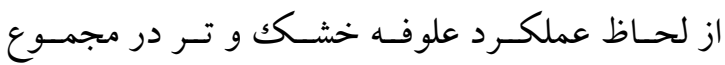
دو سال داراى برترى بوده و براى مشهد شناسايى شـدند (جدول ه). بهطور كلى در شـرايط محيطى، بايـدارى

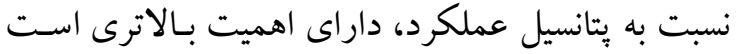

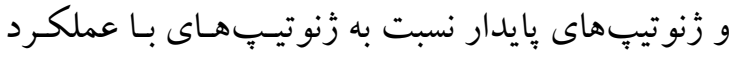

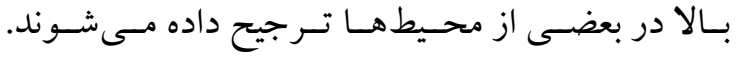

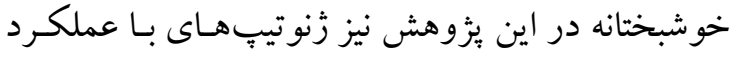

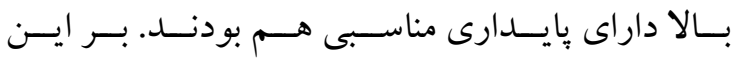

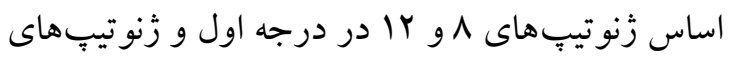

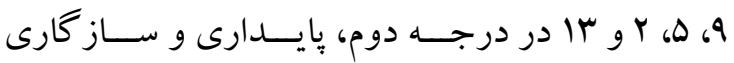

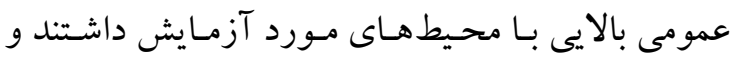

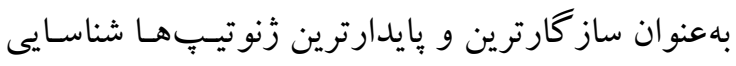

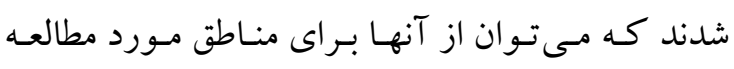

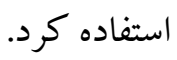

اولين مؤلفه اصلى زنوتيّها و محيطها (شكلهـاى Y و

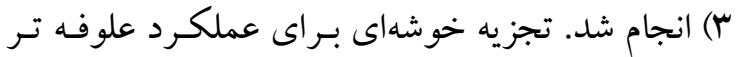

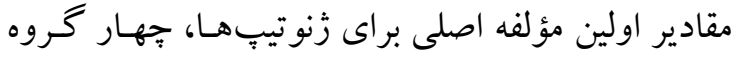

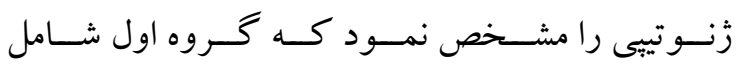

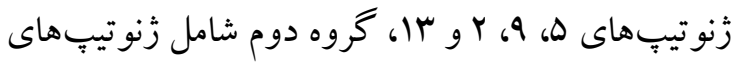

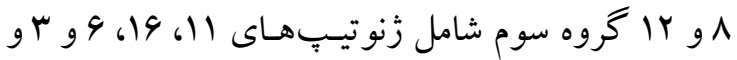

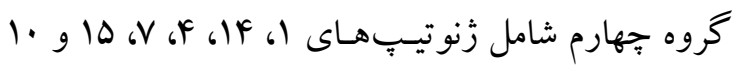

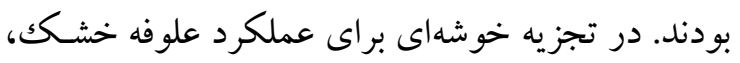

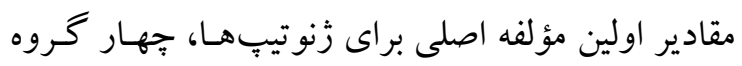

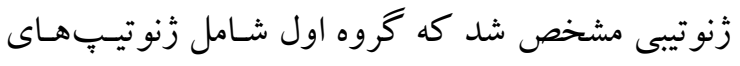

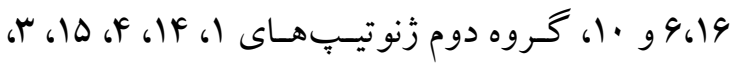

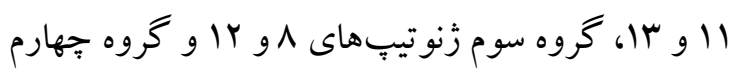

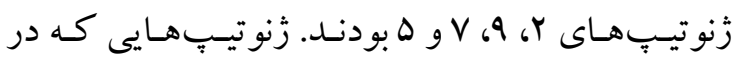

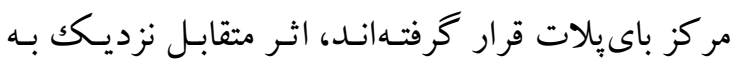
صفر را دارند و داراى بايدارى عمومى بيشـترى هستـند.

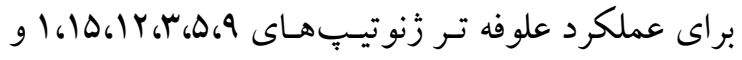

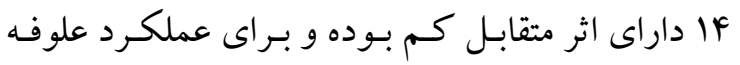

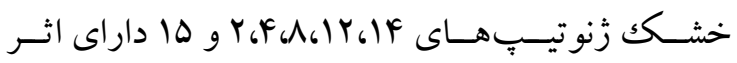

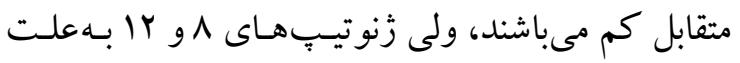

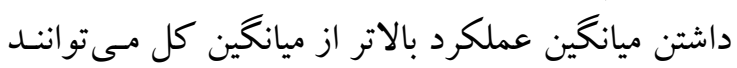

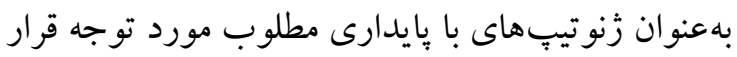
كيرند. محققان، يارامتر ارزش بِايدارىامى (ASV) را بـراى

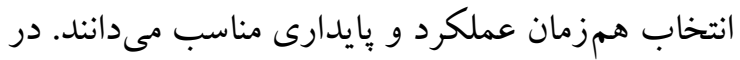

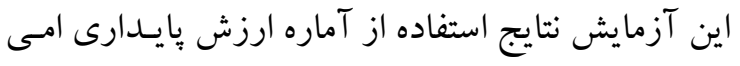

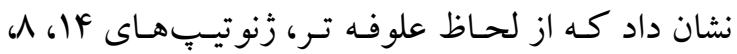

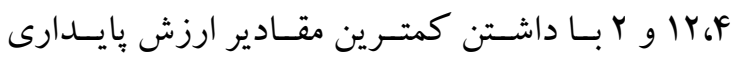

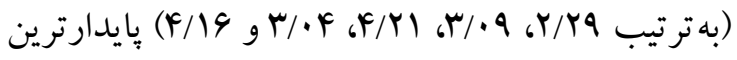

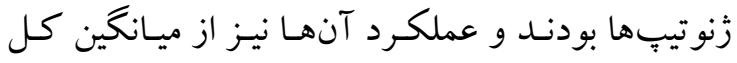

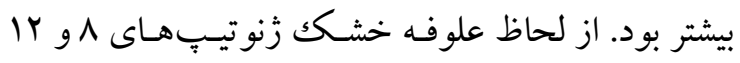

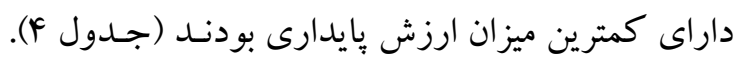

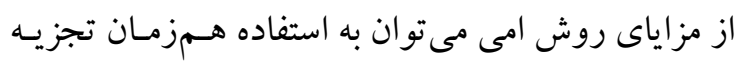




$$
\text { " ارزيابى بايدارى عملكرد زنوتيبهاى سور گوم ..." }
$$

References

منابع مورد استفاده

Abamuf, J. and A. Allurik. 1998. AMMI analysis of rainfed lowland rice (Oryza sativa) traits in Nigeria. Plant Breed. 117: 395-397.

Al-Naggar, A. M. M., R. M. Abd El-Salam, M. R. Asran and Y. S. Yaseen. 2018. Yield adaptability and stability of grain sorghum genotypes across different environments in Egypt using AMMI and GGE-biplot models. Annu. Res. Rev. Biol. 23(3): 1-16.

Basafa, M., M. Taherian and A. Beheshti. 2015. Stability analysis for forage yield in sorghum lines. Agron. J. (Pashohesh \& Sazendagi), 107: 99 -107. (In Persian with English abstract).

Dogget, H. 1988. Sorghum (2nd). Longman. ScientificTechnical. England.

FAO. 2016. FAO data based [online]. Available at, http://faostat.fao.org

Gauch, H. G. 1988. Model Selection and validation for yield trials with interaction. Biometrics, 44: 705-715.

Gauch, H. G. 1992. Statistical Analysis of Regional Yield Trials: AMMI Analysis of Factorial Designs. Elsevier, Netherlands, Amsterdam, pp. 256.

Katsura, K., Y. Tsujimoto, M. Oda, K. I. Matsushima, B. Inusah, W. Dogbe and J. I. Sakagami. 2016 . Genotype - by - environments interaction analysis of rice (Oryza spp) yield in a flood plain ecosystem in West Africa. Europ. J. Agron. 73: 152- 159.

Purchase, J. L. 1997. Parametric Analysis to Describe Genotype $\times$ Environment Interaction and Yield Stability in Winter Wheat. PhD Thesis, Department of Agronomy, Faculty of Agriculture of the University of the Free State, Bloemfontein, South Africa.

Roostaei, M., R. Mohammadi and A. Amri. 2014. Rank correlation among different statistical models in ranking of winter wheat genotypes. Crop J. 2:154-163.

Shiri, M.R. 2016. Evaluation of fresh and dry forage yield stability of forage sorghum varieties (Sorghum bicolor L. Moench) in different conditions. Journal of crop breeding Vol.8, No.19. PP:93 - 101.

Smith, C. W. and R. A. Frederiksen. 2000. Sorghum: Origin, History, Technology, and Production. John Wiley \& Sons Inc., New York, USA. pp. 840.

Tarakanovas, P. and V. Ruzgas. 2006. Additive main effect and multiplicative interaction analysis of grain yield of wheat varieties in Lithuania. Agric. Res. 4: 91-98.

Yan, W. and L. A. Hunt. 2002. Biplot analysis of multi-environment trial data, In: M. S. Kang, (Ed.), Quantitative Genetics, Genomics and Plant Breeding. CAB International, Willingford. 


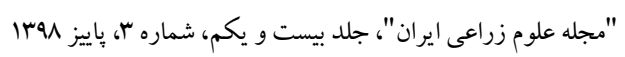

\title{
Evaluation of yield stability of forage sorghum [Sorghum bicolor (L.) Moench] genotypes using AMMI analysis
}

\author{
Khazaei. A. ${ }^{1}$, M. Torabi ${ }^{2}$, H. Mokhtararpour ${ }^{3}$ and A. R. Beheshti ${ }^{4}$
}

\begin{abstract}
Khazaei. A., M. Torabi, H. Mokhtararpour and A. R. Beheshti. 2019. Evalaution of yield stability of forage sorghum [Sorghum bicolor (L.) Moench] genotypes using AMMI analysis. Iranian Journal of Crop Sciences. 21 (3): 225-236. (In Persian).

Sorghum is an important forage crop used as silage, fresh forage and dry forage. To evaluate the yield stability of 16 genotypes; cultivars, lines and hybrids, of forage sorghum, experiments were conducted using randomized complete block design with three replications during 2016-17 at Karaj, Isfahan, Gorgan, and Mashhad field stations, Iran. The results of combined analysis of variance showed that the effect of location, year, genotype and their interactions were significant on forage yield. Mean comparison showed that hybrids No. 8 (Siloking) and 12 (FGCSI12) were superior to other genotypes with 130.6 and 127.5 t.ha ( $^{-1}$ of fresh forage yiled, and 26.97 and 27.17 t.ha ${ }^{-1}$ of dry forage yield, respectively. The hybrid No. 2 (Speedfeed), No. 9 (PHFS27), No. 5 (Juicy Sweet BMR SSH.1) and No. 13 (Sucarose- Photo- BMR) had also high fresh forage yield of 105.6, 107.8, 108.2 and $107 \mathrm{t} . \mathrm{ha}^{-1}$, respectively. The analysis of variance by AMMI method and fitting of principal components to the interaction effects of genotype and environment showed that the two principal components were significant for fresh and dry forage yield. According to the AMMI model and AMMI stability value (ASV), genotypes No. 8 (Siloking) and 12 (FGCSI12) with the high yield and stability were identified as suitable genotypes.
\end{abstract}

Key words: AMMI analysis, Sorghum, Forage yield and Principal components.

\footnotetext{
Received: December, 2018 Accepted: November, 2019

1. Assistant Prof., Seed and Plant Improvement Institute, Agricultural Research, Education and Extension Organization (AREEO), Karaj, Iran (Corresponding author) (Email: az42095@yahoo.com)

2. Assistant Prof., Agricultural and Natural Resources Research and Education Center of Isfahan, Agricultural Research, Education and Extension Organization (AREEO), Isfahan, Iran

3. Assistant Prof., Agricultural and Natural Resources Research and Education Center Golestan, Agricultural Research, Education and Extension Organization (AREEO), Gorgan, Iran

4. Associate Prof., Agricultural and Natural Resources Research and Education Center of Khorasan Razavi, Agricultural Research, Education and Extension Organization (AREEO), Mashhad, Iran
} 